\title{
ASO Visual Abstract: Prognostic Effect of Aberrant Right Hepatic Artery with Pancreaticoduodenectomy-Focus on Hepatic Recurrence
}

\author{
Christopher W. Mangieri, MD $\mathbb{D}^{\text {, }}$, Cristian D. Valenzuela, MD, Richard A. Erali, MD, Perry Shen, MD, \\ Russell Howerton, MD, and Clancy J. Clark, MD \\ Department of Surgery, Surgical Oncology Section, Wake Forest University Baptist Medical Center, Winston-Salem
}

This study evaluated the prognostic effect of aberrant right hepatic artery (aRHA) anatomy on outcomes following pancreaticoduodenectomy, with the specific focus on hepatic recurrence (https://doi.org/10.1245/s10434-02211341-6). An aRHA was found to be associated with inferior survival outcomes, which is most likely due to the significantly increased risk of hepatic metastatic recurrence with aberrant anatomy. While utilization of systemic therapy was found to equilibrate overall survival (OS) and disease-free survival (DFS) outcomes, it had a more subtle effect on limiting hepatic spread of disease. Study findings suggest potential to expand consideration for systemic therapy for patients with aRHA anatomy. This analysis provides important prognostic information for a commonly encountered anatomic variant.

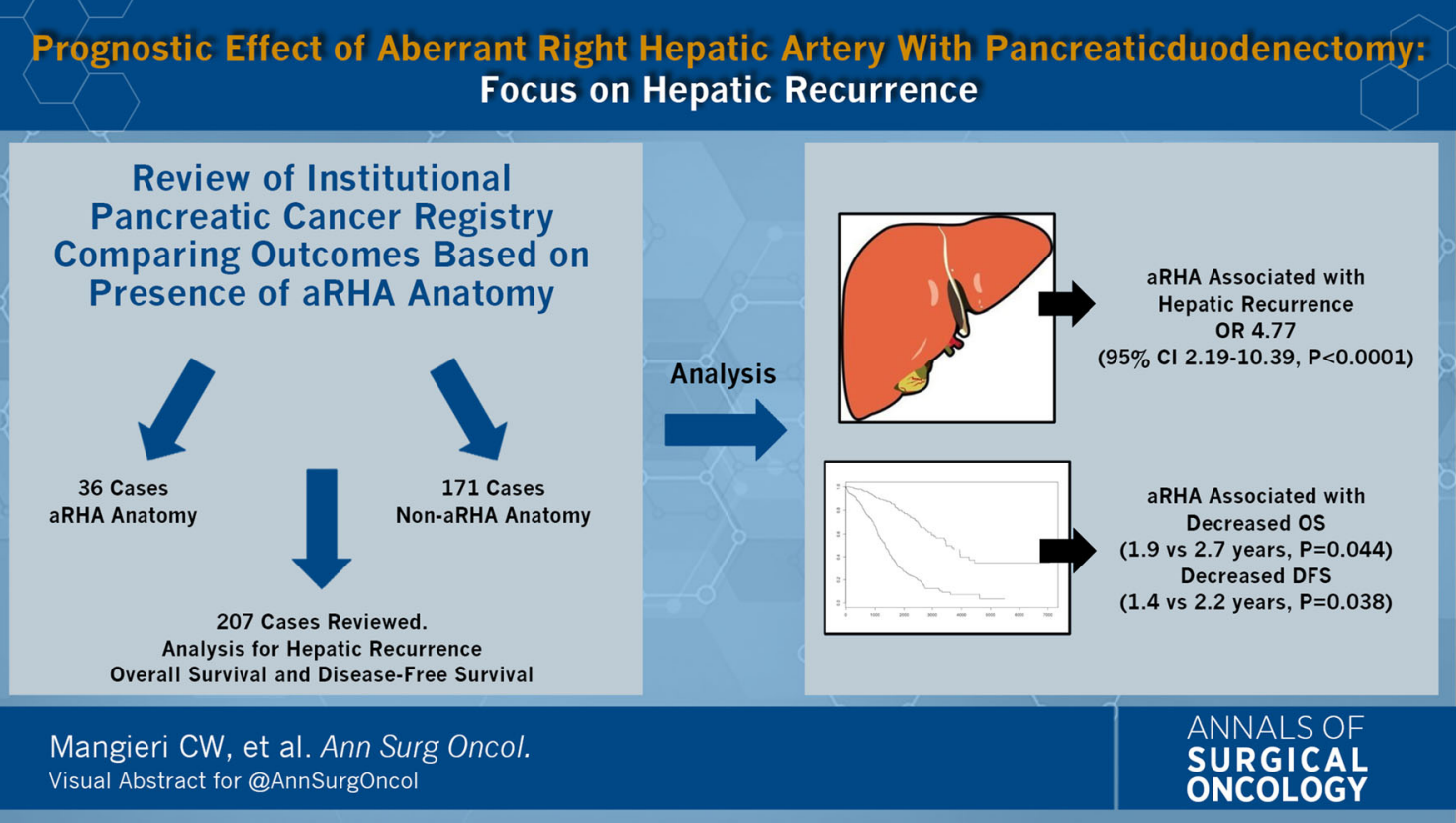

DISCLOSURE None of the authors have any conflicts of interest.

(C) Society of Surgical Oncology 2022

Publisher's Note Springer Nature remains neutral with regard to C. W. Mangieri, MD

e-mail: cmangier@wakehealth.edu jurisdictional claims in published maps and institutional affiliations. 